सक्षा

Transaction

.

(Received August 20, 1996)

\title{
Properties of Handsheets Containing Cellulose Regenerated from Cellulose/Aqueous $\mathrm{NaOH}$ Solution
}

\begin{abstract}
Akira Isogai
Graduate School of Agriculture and Life Science. The University of Tokyo, Bunkyo-ku, Tokyo, 113 Japan

Abstract : Microcrystalline cellulose was dissolved in aqueous $\mathrm{NaOH}$ by the freezing-defrosting-diluting procedure, and its never-dried regenerated cellulose gel was prepared from the aqueous $\mathrm{NaOH}$ solution. Handsheets were then prepared from mixtures of bleached kraft pulp and the regenerated cellulose gel. Mechanical, optical and sizing properties of the handsheets thus prepared were studied in terms of the re. generated cellulose content. Young's modulus and tensile and tearing indices of the handsheets increased with the regenerated cellulose content from 0 to $10 \%$. Especially, folding endurance drastically increased by the addition of the regenerated cellulose. On the other hand, opacity and sizing degrees decreased with the regenerated cellulose content.
\end{abstract}

\section{Introduction}

Nowadays properties of paper are controlled by var. ious methods through papermaking processes in order to approach to various needs for paper and paper board qualities. The wet-end control is one of the significant processes not only for approaching the suitable papermaking systems but also for adjusting the required paper qualities. Partial replacement of wood pulps to other fib. rous materials may provide some new or additional properties to papersheets.

In the previous papers, handsheets were prepared from pulp suspensions containing bleached kraft pulp (BKP) and either amorphous cellulose, microcrystalline cellulose powder or starch pulp, and fundamental properties of the handsheets such as mechanical and optical properties and sizing behavior were studied in terms of the content of those additives $[1,2]$. Especially, the par tial replacement of wood pulp to never-dried amorphous cellulose gel and swollen starch pulp improved some mechanical properties of the handsheets thus prepared.

Recently, Kamide et al. reported that steam-exploded bleached sulfite pulps were soluble in $9 \% \mathrm{NaOH}$ solu tions at $4{ }^{\circ} \mathrm{C}[3 \cdot 6]$. Furthermore, detailed conditions for complete dissolution of microcrystalline cellulose and some swollen celluloses in aqueous $\mathrm{NaOH}$ solutions were investigated by Isogai and Atalla [7]. Microcrystalline cellulose powder was completely dissolved in $5.9 \%$ aqueous $\mathrm{NaOH}$ solutions under the reported conditions. The regenerated cellulose, obtained from the microcrystalline cellulose powder/aqueous $\mathrm{NaOH}$ solution by neutralization. filtration, washing and drying, had the cellulose II structure with crystallinity index of $30.40 \%$ (7). However, since microcrystalline cellulose had a degree of polymerization (DPv) of 200-250, it was impossible to prepare fibers or films having sufficient mechanical properties from this cellulose sample. On the other hand, the regenerated cellulose gel, that was pre pared from a microcrystalline cellulose powder/aqueous $\mathrm{NaOH}$ solution, may be applicable to wet-end additives as some binders of wood pulps in papersheets.

In this paper, therefore, a regenerated cellulose gel was prepared from a cellulose/aqueous $\mathrm{NaOH}$ solution, and handsheets were prepared from pulp suspensions containing the cellulose gel. Drainage behavior of the sus pension and some fundamental properties of the hand sheets thus prepared were studied in terms of the roles of the regenerated cellulose component in pulp suspen sions and in papersheets.

\section{Experimental}

\subsection{Materials}

Microcrystalline cellulose powder (Cellulose Powder A, Advantec Toyo Co. Ltd.) was used as a cellulose sam ple. Commercial hardwood BKP was beaten to $500 \mathrm{~mL}$ Canadian Standard Freeness using a PFI mill. 
The microcrystalline cellulose was dissolved in a $6 \%$ $\mathrm{NaOH}$ solution, according to the method reported by Isogai and Atalla [7]. Namely, the cellulose sample ( $1 \mathrm{~g}$ ) was soaked in an $8.75 \% \mathrm{NaOH}$ solution $(34 \mathrm{~g})$, and the mixture was frozen at $-20^{\circ} \mathrm{C}$. Then the frozen sample was defrosted at room temperature, and water (15 g) was added to the mixture with vigorous stirring for obtaining a clear cellulose solution. The solution was poured into acidic water, and regenerated cellulose gel with heterogeneous shape was obtained. This regenerated and never-dried cellulose gel was washed thoroughly with water by filtration, and was converted to fine gel particles using a blender [1].

Handsheets containing the regenerated cellulose were prepared according to TAPPI Test Methods [8], with a target of $60 \mathrm{~g}$ basis weight ; a designed amount of the re generated cellulose was added to pulp suspension as partial replacement of BKP. An alkylketene dimer emulsion and polyamideamine-epichlorohydrin resin (AS 202 and WS 570, respectively, Japan PMC. Co. Ltd.) were added in this order to the pulp suspension with addition levels of 0.2 and $0.1 \%$, respectively, on dry weight of total pulp (BKP + the regenerated cellulose). The wet-pressed handsheets were dried at $120{ }^{\circ} \mathrm{C}$ for 2 min using a drum dryer. Regenerated cellulose content in handsheets was calculated from basis weight of the handsheets.

\subsection{Measurements}

Dynamic Young's modulus of the handsheets was re corded using a Dynamic Modulus Tester PPM-5R (H. M Morgan Co. Ltd.). Tearing resistance was measured us ing an Elmendorf tester according to the procedure re ported in TAPPI Test Methods [9]. Hitachi S-4000 was used for obtaining scanning electron micrographs of the handsheets. The content of alkylketene dimer (AKD) in handsheets was determined by pyrolysis-gas chroma tography (Yanaco GP-1018 and Shimadzu GC-14B) us ing a capillary column of OV-1 $(60 \mathrm{~m} \times 0.25 \mathrm{~mm})$ under the following conditions : pyrolysis temperature ; $500{ }^{\circ} \mathrm{C}$ injection and detector temperatures ; 250 and $280{ }^{\circ} \mathrm{C}$, respectively. The column temperature was initially set at $200{ }^{\circ} \mathrm{C}$ and was heated up to $300{ }^{\circ} \mathrm{C}$ at $5{ }^{\circ} \mathrm{C} / \mathrm{min}$. AKD content in handsheets was calculated on the basis of peak areas due to AKD components and total peak areas, according to the calibration curve obtained previously $[10,11]$. Other methods and conditions for obtaining fundamental properties of handsheets were described in

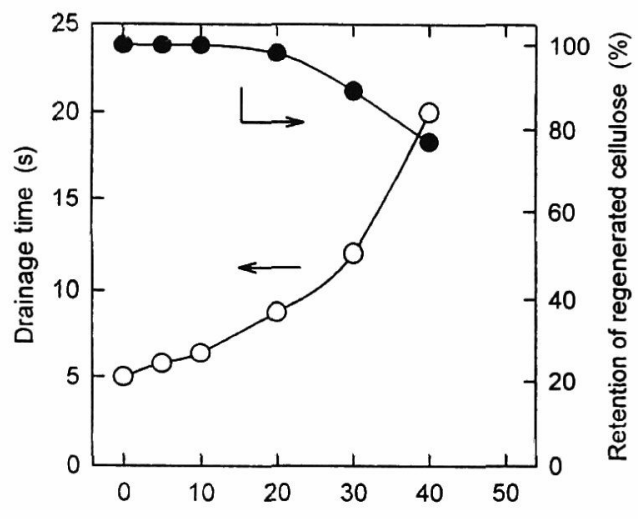

Regenerated cellulose added (\% in total pulp)

Fig. 1 Drainage time of BKP-regenerated cellulose suspension in Tappi handsheet-making procedure, and retention $(\%)$ of regenerated cellulose on handsheets.

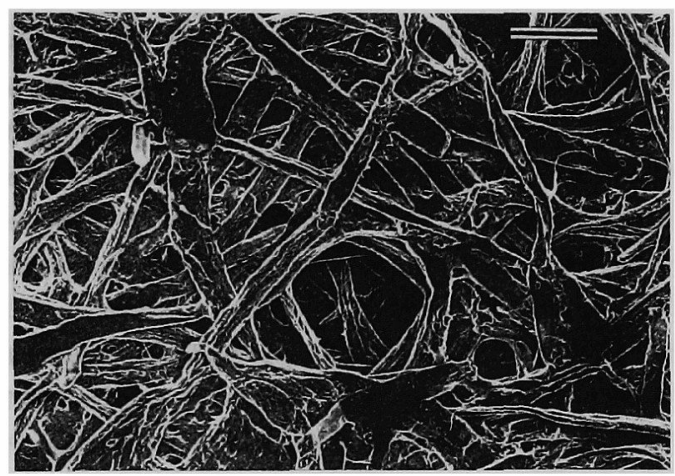

Fig. 2 Scanning electron microphotograph of handsheet containing regenerated cellulose of $27 \%$. Scale bar corresponds to $0.5 \mathrm{~mm}$

the previous papers $[1,2]$.

\section{Results and Discussion}

\subsection{General Observation}

Optical micrographs of the regenerated cellulose used in this study showed that it was fine and swollen gel with smaller than $0.1 \mathrm{~mm}$ in size, and the particle shape was quite similar to that of the never-dried and regenerated amorphous cellulose gel [1]. Drainage time increased with the regenerated cellulose content in pulp suspension (Fig. 1.). Amounts of the regenerated cellulose retained in the handsheets were almost $100 \%$ at 5 $20 \%$ addition levels and then decreased at the further addition levels (Fig. 1). Most of the regenerated cellulose gel particles, added to the pulp suspension at $5.20 \%$ 


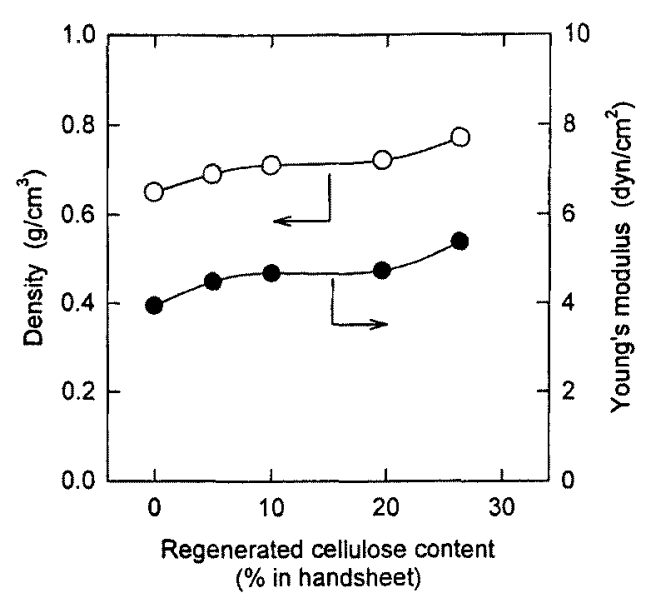

Fig. 3 Density and Young's modulus of handsheets containing regenerated cellulose.

addition levels, were physically entangled in the BKP. fiber mat during the handsheet-making, and the ceilulose gel particles were partly lost in the drainage water at $30.50 \%$ addition levels. Moisture content of the handsheets was almost constant, about $8 \%$, at the $0.27 \%$ regenerated cellulose content ; moisture content of the regenerated cellulose in the handsheets after drying was almost similar to that of BKP fibers.

Fig. 2 shows scanning electron micrographs of a handsheet surface containing the regenerated cellulose of 27 $\%$. No particular particles originating from the regenerated cellulose were observed on the surface; the regener. ated cellulose was sufficiently mixed with BKP fibers and might be present in handsheets as tightly combined form, like thin films, with BKP fibers.

\subsection{Mechanical Properties}

Fig. 3 shows density and dynamic Young's modulus of the handsheets. The pattern of density corresponded well with that of Young's modulus. These two properties increased with the regenerated cellulose content from 0 to $10 \%$ and from 19 to $27 \%$. Thus, the regenerated cellulose gel may have an effect of increasing interfiber bond. ing in handsheets.

Tensile index and elongation of the handsheets were shown in Fig. 4. These patterns were slimier to those of density and Young's modulus of the handsheets, as shown in Fig. 3. A clear effect of increasing tensile index was observed even at the regenerated cellulose content of $5 \%$. However, almost constant values of tensile index were obtained for handsheets at the regenerated cellulose

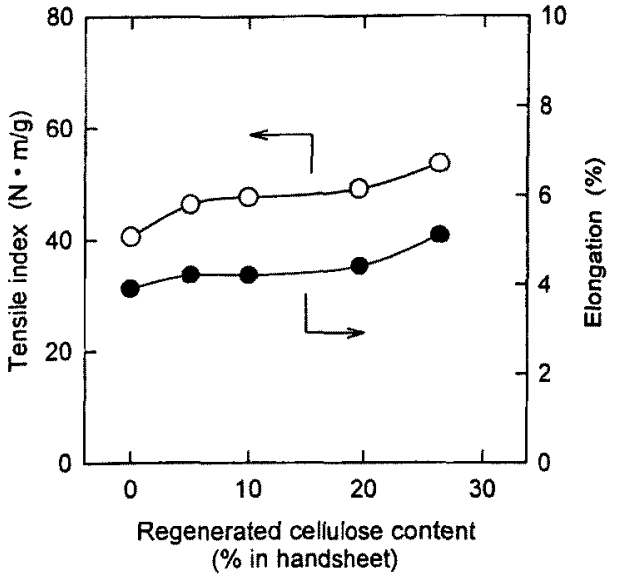

Fig. 4 Tensile index and elongation of handsheets containing regenerated cellulose.

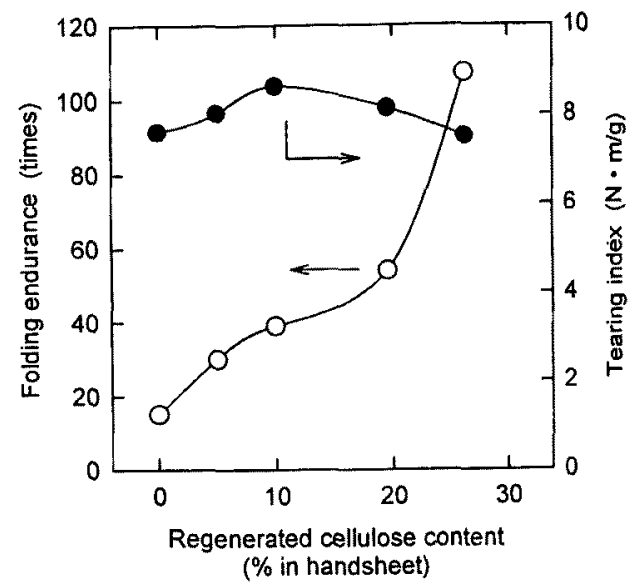

Fig. 5 Folding endurance and tearing index of handsheets containing regenerated cellulose.

content of $5.20 \%$. Probably the decrease in the number of BKP fibers in the handsheets with increasing the re. generated cellulose content at 5-20\% resulted in the pat. tern shown in Fig. 4 by the balance between the two opposite effects ; one is the effect of increasing interfiber bonding by the regenerated cellulose gel and another is the effect of decreasing tensile index by diminishing the number of BKP fibers.

Fig. 5 shows folding endurance and tearing index of the handsheets. It is known that tearing index has strong dependence on the number of fibers in sheet [12]. Although the number of BKP fibers decreased with the increase in the regenerated cellulose content, tearing in dex increased at the regenerated cellulose content up to 


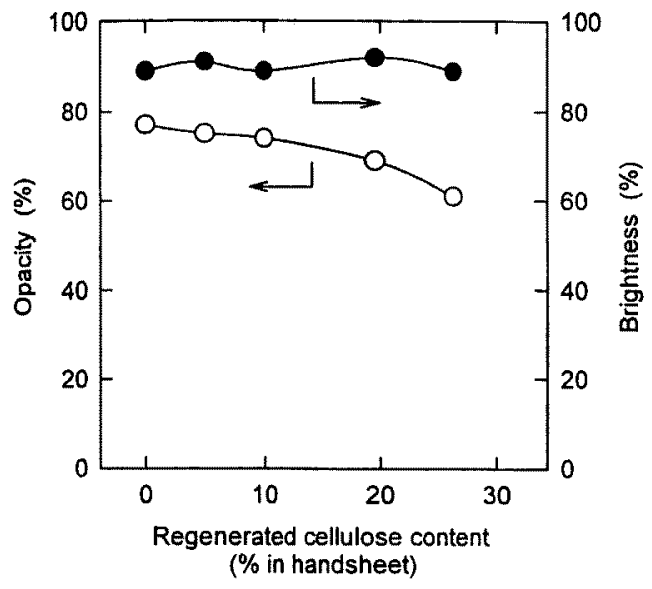

Fig. 6 Printing opacity and brightness of handsheets containing regenerated cellulose.

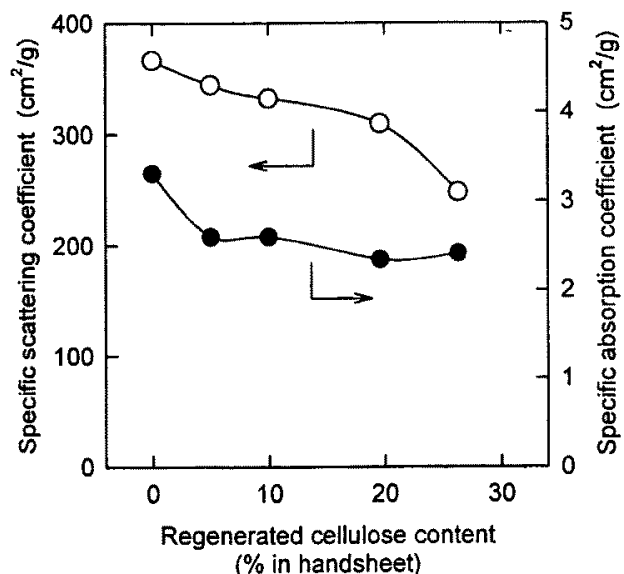

Fig. 7 Specific scattering coefficients and specific absorption coefficients of handsheets containing regenerated cellulose.

$10 \%$ and then decreased. Even at the regenerated cellu lose content of $27 \%$, the handsheet had a tearing index almost equal to that of the handsheet prepared only with BKP. Thus, the regenerated cellulose is effective for in creasing both tensile and tearing indices of the handsheets at the regenerated cellulose content of $5-10 \%$ by the effect of increasing interfiber bonding. A clear increase in folding endurance was observed for the handsheets. As reported previously, never-dried amorphous cellulose gel and starch pulp also had the effect of increasing folding endurance, where moisture content of handsheets increased with these additives in those cases

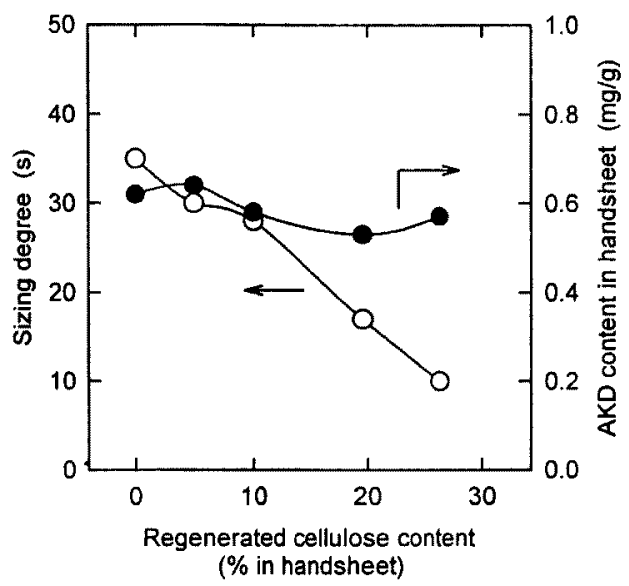

Fig. 8 Sizing degrees and AKD content of handsheets containing regenerated cellulose.

$[1,2]$. On the other hand, since the presence of the re generated cellulose in handsheet had no influence on changes in moisture content, the increase in folding endurance shown in Fig. 5 is primarily due to the increase in interfiber bonding by the presence of the regenerated cellulose in the handsheets.

\subsection{Optical and Sizing Properties}

Printing opacity and brightness of the handsheets are shown in Fig. 6. Brightness was almost constant at the regenerated cellulose content of $0.27 \%$. On the other hand, opacity decreased with the increase in the regener ated cellulose because of the increase in interfiber bond ing [13].

Fig. 7 shows specific absorption coefficients $\left(K^{\prime}\right)$ and specific scattering coefficients $\left(S^{\prime}\right)$ of the handsheets. Scattering coefficients have linear relation to specific surface area of the papersheets, when they consist of the same components [14]. Since specific scattering coeffi cients of the handsheets decreased with the increase in the regenerated cellulose content, interfiber bonding in the handsheets must be reinforced by the regenerated cellulose. Specific absorption coefficients of the handsheets were low and almost constant values at the regenerated cellulose content of $0.27 \%$

These changes of optical properties of handsheets by the addition of the regenerated cellulose gel to pulp suspension were similar to those obtained for the handsheets prepared with never-dried amorphous cellulose gel and starch pulp $(1,2)$, which also had the effect of in- 
creasing interfiber bonding.

Fig. 8 shows sizing behavior of the handsheets containing the regenerated cellulose. Sizing degrees clearly decreased with the increase in the regenerated cellulose content, although AKD content was almost constant. Similar results were observed for the handsheets prepared with the never-dried amorphous cellulose gel and starch pulp $[1,2]$. At this point, the reason for the decrease in sizing degrees by the addition of the regenerated cellulose has not been clarified.

\section{Conclusions}

The regenerated cellulose gel prepared from a microcrystalline cellulose/aqueous $\mathrm{NaOH}$ solution was applied to a wet-end additive of papermaking. On the basis of the results obtained in this study, the regenerated cellulose gel had the effect of increasing interfiber bonding in papersheets, particularly at $5-10 \%$ addition levels : folding endurance and tensile and tearing indices were improved by the addition. However, printing opacity and sizing degrees decreased by the regenerated cellulose additions. These results were similar to those of handsheets prepared by the addition of never-dried amorphous cellulose gels to pulp suspension (1). Therefore, never-dried regenerated cellulose gel particles are effective in reinforcing interfiber bonding in papersheet.

\section{References}

1. A. Isogai, F. Onabe, and M. Usuda, Sen'i Gakkaishi,
48, 281 (1992).

2. K. Okomori, A. Isogai, J. Yoshizawa, and F. Onabe, Nordic Pulp Paper Res. J., 9, 237 (1994).

3. K. Kamide and K. Okajima, U. S. Pat. 4,634,470 (1987).

4. T. Yamashiki, T. Matsui, M. Saitoh, K. Okajima, K. Kamide, and T. Sawada, British Polym. J. 22, 73 (1990).

5. T. Yamashiki, T. Matsui, M. Saitoh, Y. Matsuda, K. Kamide, and T. Sawada, British Polym. J. 22, 201 (1990).

6. T. Yamashiki, T. Matsui, M. Saitoh, K. Okajima, K. Kamide, and T. Sawada, British Polym. J. 22, 121 (1990).

7. A. Isogai and R, H. Atalla, U. S. Pat. $5,410,034$ (1995).

8. TAPPI Test Method, T 205 om-88 (1991).

9. TAPPI Test Methods $T 414 \mathrm{om} \cdot 88$ (1988).

10. A. Isogai, R. Taniguchi, F. Onabe, and M. Usuda, Nor. dic Pulp Paper Res. J., 7, 193 (1992).

11. A. Isogai, M. Nishiyama, and F. Onabe, Sen'i Gak. kaishi, 52, 195 (1996).

12. C. E. Brandon, "Pulp and Paper", (J. P. Casey, Ed.) John Wiley \& Sons, New York, p. 1799 (1981).

13. C. E. Brandon, "Pulp and Paper", (J. P. Casey, Ed.), John Wiley \& Sons, New York, p. 1873 (1981).

14. C. E. Brandon. "Pulp and Paper", (J. P. Casey, Ed.) John Wiley \& Sons, New York, p. 1858 (1981). 